\title{
PELATIHAN PERSIAPAN MENGHADAPI DUNIA KERJA BAGI MAHASISWA LULUSAN BARU
}

\author{
Rizky Nastiti ${ }^{1 *}$, Tri Ramaraya Koroy ${ }^{2}$, Devi Rusvitawati ${ }^{3}$, Ninuk Krismanti ${ }^{4}$, \\ Yulieda Hermaniar ${ }^{5}$ \\ ${ }^{1,2}$ STIE Indonesia Banjarmasin \\ ${ }^{3}$ STIMI Banjarmasin \\ ${ }^{4,5}$ STKIP PGRI Banjarmasin \\ *E-mail: rizky@ stiei-kayutangi-bjm.ac.id
}

\begin{abstract}
ABSTRAK
Semakin ketatnya persaingan kerja membuat mahasiswa yang baru lulus kuliah menghadapi kesulitan untuk mendapatkan perkerjaan yang mereka impikan. Sehingga, pembekalan diri bagi lulusan yang akan memasuki dunia kerja kini menjadi semakin penting. Oleh karena itu, pengabdian kepada masyarakat ini bertujuan untuk memberikan keterampilan bagi fresh graduate agar dapat mempersiapkan diri dengan lebih baik sebelum melamar pekerjaan. Pelatihan yang dilakukan secara daring ini menargetkan agar fresh gradute menjadi lebih siap dalam bersaing mencari pekerjaan. Pemberian materi dilakukan oleh dua orang narasumber yang kompeten, yaitu seorang psikolog yang telah berpengalaman di bidangnya dan seorang direktur utama Bank daerah. Setelah mengikuti pelatihan ini, para lulusan mendapatkan pengetahuan mengenai tips dan trik menghadapi tes wawancara dan psikotes. Sehingga, mereka menjadi lebih percaya diri dan termotivasi untuk bersaing dalam mencari pekerjaan.
\end{abstract}

Kata kunci: pelatihan, dunia kerja, mahasiswa lulusan baru

\section{TRAINING ON PREPARATION FOR THE WORLD OF WORK FOR FRESH GRADUATES}

\begin{abstract}
Increasing job competition leds the fresh graduates face difficulties in getting the job they dream of. Hence, selfprovision for fresh graduates who will enter the world of work is now becoming increasingly important. Therefore, this community service aims to provide skills for fresh graduates so that they can prepare themselves better before applying for jobs. This online training aims to make the fresh gradute better prepared for job competition. The training was led by two competent speakers, an experienced psychologist and a president director of a regional bank. After attending this training, the graduates gain knowledge about tips and tricks for facing interviews and psychological tests. Thus, they become more confident and motivated to compete in job seeking.
\end{abstract}

Keywords: training, world of work, fresh graduates

\section{PENDAHULUAN}

Di era persaingan saat ini, pencari kerja harus melengkapi kemampuannya dengan kompetensi kerja. Sehingga, bisa lebih mudah menentukan lapangan pekerjaan sesuai bakat, minat, dan keinginannya. Bagi fresh graduate, lulus kuliah bukan berarti perjuangan selesai. Mereka masih harus berjuang lagi untuk mendapat pekerjaan yang justru lebih menantang dibanding perjuangan untuk lulus kuliah.

Mendapatkan pekerjaan setelah menyandang gelar sarjana adalah sebuah keharusan. Para fresh graduate ini dituntut untuk mendapatkan pekerjaan di tengah persaingan ketat dunia kerja. Mereka harus berkompetisi, tidak hanya dengan sesama fresh graduate, tapi juga dengan pencari kerja yang sudah berpengalaman di bidangnya. Hal ini membuat perjuangan fresh graduate mendapatkan 
pekerjaan impian semakin sulit. Padahal, jika ditinjau dari perspektif logika, menjadi seorang sarjana seharusnya memiliki kemampuan lebih dibandingkan yang bukan lulusan sarjana. Seorang sarjana harusnya mampu berpikir inovatif, kontruktif, dan kreatif. Sarjana seharusnya menjadi pelopor, tidak hanya mampu menunggu kesempatan.

Selain itu, pada kenyataannya, masih banyak fresh graduate yang masih belum bisa memenuhi persyaratan pasar kerja. Karenanya, mendapatkan pekerjaan setelah lulus masih menjadi tantangan besar bagi mahasiswa (Nghi dan Hien, 2020). Padahal, salah satu hal yang harus dilakukan generasi intelektual, terutama lulusan perguruan tinggi adalah mampu memperoleh pekerjaan bahkan membuka lapangan pekerjaan untuk mengurangi pengangguran. Lebih lanjut lagi, menurut Nurullaili (2019) secara umum terdapat beberapa kendala yang dihadapi oleh penggangguran terdidik dalam mendapatkan pekerjaan meliputi berbagai macam kendala seperti, jenis pendidikan yang tidak umum sehingga kurang diminati dunia kerja, kecurangan dalam dunia kerja, menikah sehingga membatasi kegiatan, tidak adanya modal usaha yang tersedia, dan kemalasan.

Nurjanah (2018) menambahkan bahwa mahasiswa fresh graduate cenderung lebih cemas menghadapi proses melamar kerja dibanding menganggur. Hal ini disebabkan banyak faktor yaitu kurangnya soft skill yang dimiliki mahasiswa, kurangnya informasi mengenai pekerjaan dan kurangnya kepercayaan terhadap kemampuan diri sendiri. Selain itu, banyak fresh graduate yang gagal mendapatkan pekerjaan karena menyepelekan persyaratan dan tidak mempersiapkan diri terlebih dahulu sebelum melamar kerja tanpa menyesuaikan dengan apa yang dibutuhkan. Perusahaan seringkali meragukan kemampuan fresh graduate karena umumnya mereka tidak memiliki pengalaman di dalam dunia kerja.

Salah satu penyebab utama kegagalan dalam mendapatkan kerja adalah kegagalan di tahap tes wawancara. Krishnan dkk (2017) menyatakan bahwa sebagian besar lulusan baru gagal memberikan kesan yang baik saat wawancara. Mereka bahkan tidak dapat memahami pertanyaan wawancara dasar yang diajukan oleh sebagian besar pemberi kerja. Ketidakmampuan ini menyebabkan kelemahan sosial dan ekonomi, terkait dengan pencapaian pekerjaan.

Aisyah (2019) mengemukakan beberapa persiapan yang harus dilakukan sebelum wawancara kerja antara lain memahami posisi jabatan yang dikehendaki dan menguasai profil perusahaan yang dilamar. Hal ini bertujuan agar pelamar dapat menjawab pertanyaan wawancara dasar yang diajukan dengan lancar. Selain itu, memahami potensi diri yang dimiliki serta melakukan simulasi wawancara juga dapat membantu pelamar terutama fresh graduate agar menjadi lebih siap dalam menghadapi tes wawancara.

Berdasarkan uraian di atas, maka dapat ditarik kesimpulan bahwa persiapkan diri yang matang merupakan salah satu hal utama yang harus dimiliki oleh fresh graduate. Mereka harus mampu menghadapi berbagai tahapan tes yang menjadi persyaratan, seperti tes wawancara dan psikotes. Menyadari situasi tersebut, kegiatan pengabdian kepada masyarakat ini bertujuan untuk meningkatkan kemampuan lulusan dalam menghadapi persaingan membuat usaha maupun dalam mencari pekerjaan. Selain itu, kegiatan ini diharapakan dapat memberikan pembekalan kepada lulusan mengenai tips dan trik menghadapi tes wawancara dan psikotes.

\section{METODE}

Mengingat kondisi yang belum kondusif karena masih dalam suasana pandemi, maka kegiatan pelatihan ini diadakan secara daring melalui aplikasi CloudX. Didasari dengan kondisi di mana fresh graduate menghadapi kesulitan dalam bersaing mencari pekerjaan, kegiatan pengabdian ini bertujuan untuk memberikan bekal bagi fresh graduate agar dapat mempersiapkan diri dengan lebih baik terutama dalam menghadapi tes wawancara dan psikotes. Metode yang digunakan dalam penyampaian materi adalah melalui ceramah dan diskusi. Narasumber juga membagikan pengalaman mereka yang dapat memotivasi peserta dalam mencari pekerjaan. 


Kecemasan dan
kurangnya rasa
percaya diri fresh
graduate dalam
mencari perkerjaan
terutama saat tes
kerja

Kecemasan dan kurangnya rasa percaya diri fresh graduate dalam mencari perkerjaa kerja

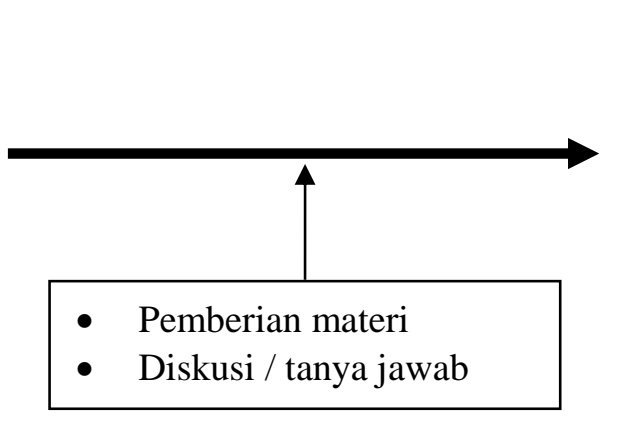

Fresh graduate menjadi lebih percaya diri, termotivasi dan siap dalam mencari perkerjaan terutama saat tes kerja

Gambar 1. Kerangka Pemecahan Masalah

Untuk mengukur tingkat ketercapaian kegiatan ini, di akhir kegiatan para peserta diminta untuk mengisi kuesioner evaluasi yang mencakup penilaian peserta terhadap pembicara, pemateri dan jalannya acara. Hasil kuesioner ini juga dijadikan sebagai bahan pertimbangan dalam mengadakan kegiatan pengabdian kepada masyarakat berikutnya.

\section{HASIL DAN PEMBAHASAN}

\section{Isi Hasil dan Pembahasan}

Kegiatan pelatihan persiapan menghadapi dunia kerja bagi mahasiswa lulusan baru Indonesia ini bertujuan memberikan pembekalan bagi mahasiswa terutama yang baru saja lulus kuliah di Banjarmasin dalam rangka menghadapi dunia kerja. Narasumber dari kegiatan ini adalah pembicara dari PT. Benefit SDM yaitu Bapak Sukma Noor Akbar, M.Psi,, Psikologi yang memang telah berpengalaman dalam menyelenggarakan tes masuk kerja bagi perusahaan maupun instansi di Kalimantan. Materi yang diberikan adalah tips dalam menghadapi psikotes dan wawancara tes masuk kerja. Pembicara kedua adalah Dr. Agus Syabarrudin, M.Si, yang merupakan Direktur Utama Bank Kalsel serta Dosen di STEI Indonesia Banjarmasin. Materi yang beliau sampaikan terkait dengan halhal yang perlu dipersiapkan oleh mahasiswa dalam melamar perkerjaan terutama di bidang perbankan. Beliau juga membagikan pengalaman beliau selama meniti karir di bidang perbankan.

Acara webinar ini disiarkan secara langsung melalui media CloudX dengan melibatkan sebanyak 70 orang peserta. Para perserta mengikuti dengan antusias dan aktif mengajukan pertanyaan yang berkaitan dengan materi yang diberikan. Dengan dilaksanakannya kegiatan ini, diharapkan mahasiswa di Kota Banjarmasin baik yang berada di tingkat akhir maupun yang baru saja lulus kuliah dapat lebih baik dalam mempersiapkan diri mereka untuk mengikuti tes masuk kerja dan memasuki dunia kerja.

Berdasarkan hasil evaluasi yang diberikan kepada peserta webinar didapatkan bahwa mereka dapat memahami dengan baik materi yang diberikan. Mereka menilai tips dan trik yang diberikan dapat berguna jika nanti mereka menghadapi tes wawancara dan tes psikotes. Selain itu, peserta juga mengharapkan pelatihan berupa simulasi agar mereka dapat lebih efektif dan efisien dalam mempersiapkan diri mereka untuk menghadapi tes masuk kerja, baik berupa tes tertulis maupun tes wawancara.

Berdasarkan kuesioner evaluasi yang diberikan kepada peserta setelah mengikuti kegiatan pelatihan, beberapa poin yang dievaluasi oleh peserta yaitu pembicara, materi, dan jalannya acara. Pada kuesioner, peserta diminta untuk memberikan penilaian dengan nilai 1 sampai 4. Berikut adalah hasil analisis dari evaluasi kegiatan oleh peserta. 
Grafik 1. Hasil Evaluasi Pelaksanaan Kegiatan

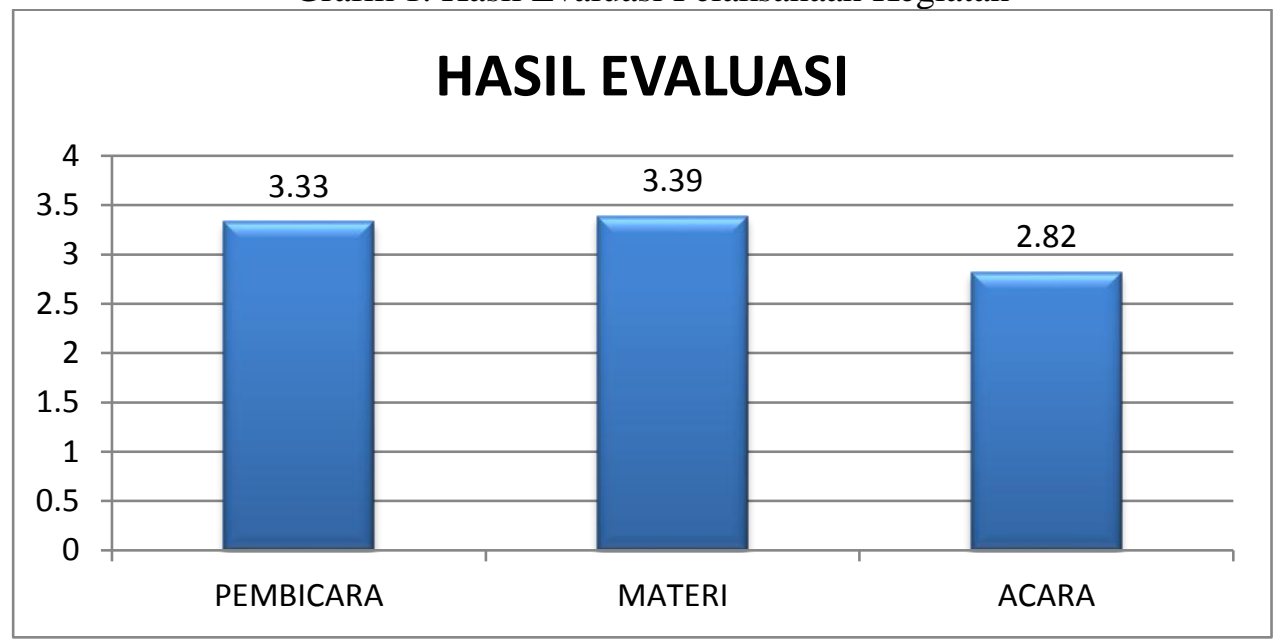

Sumber: Data diolah, 2020

Pada poin Pembicara, peserta diminta untuk menilai lima penyataan mengenai pembicara pada saat kegiatan pelatihan yang terdiri atas 1) menguasai materi, 2) komunikatif, 3) presentasi audiovisualnya menarik, 4) tepat waktu, dan 5) memberi kesempatan untuk diskusi. Berdasarkan Grafik 1, dapat dilihat bahwa peserta memberikan penilaian yang baik terhadap penguasaan materi dari pembicara. Selain itu, pembicara juga dinilai komunikatif, menarik dan tepat waktu oleh peserta. Presentasi audiovisual yang disajikan oleh pembicara juga dinilai baik oleh peserta. Pembicara juga dinilai memberikan kesempatan yang cukup untuk berdiskusi.

Pada poin Materi, peserta diminta untuk menilai lima penyataan mengenai materi yang disajikan pada saat kegiatan pelatihan yang terdiri atas 1) sasaran / tujuan kegiatan jelas, 2) bermanfaat untuk peserta, 3) sesuai dengan harapan, 4) cakupan materi memadai, dan 5) sesuai dengan perkembangan ilmu dan teknologi. Berdasarkan Grafik 1, dapat dilihat bahwa peserta memberikan penilaian bahwa materi yang disampaikan memiliki tujuan yang jelas, bermanfaat bagi peserta serta sesuai dengan harapan mereka. Selain itu, mereka menilai bahwa materi yang diberikan sudah cukup memadai serta sesuai dengan perkembangan ilmu dan teknologi.

Pada poin Jalannya Acara, peserta diminta untuk menilai lima penyataan mengenai jalannya acara kegiatan pelatihan yang terdiri atas 1) Membosankan, 2) Monoton atau kurang menarik, 3) Banyak diskusi, 4) Peserta pasif, dan 5) Tepat waktu. Berdasarkan Grafik 1, dapat dilihat bahwa peserta memberikan penilaian bahwa acara berlangsung cukup baik. Selain itu, acara dinilai berjalan tepat waktu serta tidak membosankan ataupun monoton. Peserta juga menilai kesempatan untuk berdikusi cukup memadai. Selain itu, peserta menilai kurangnya partisifasi aktif dari para peserta pelatihan.

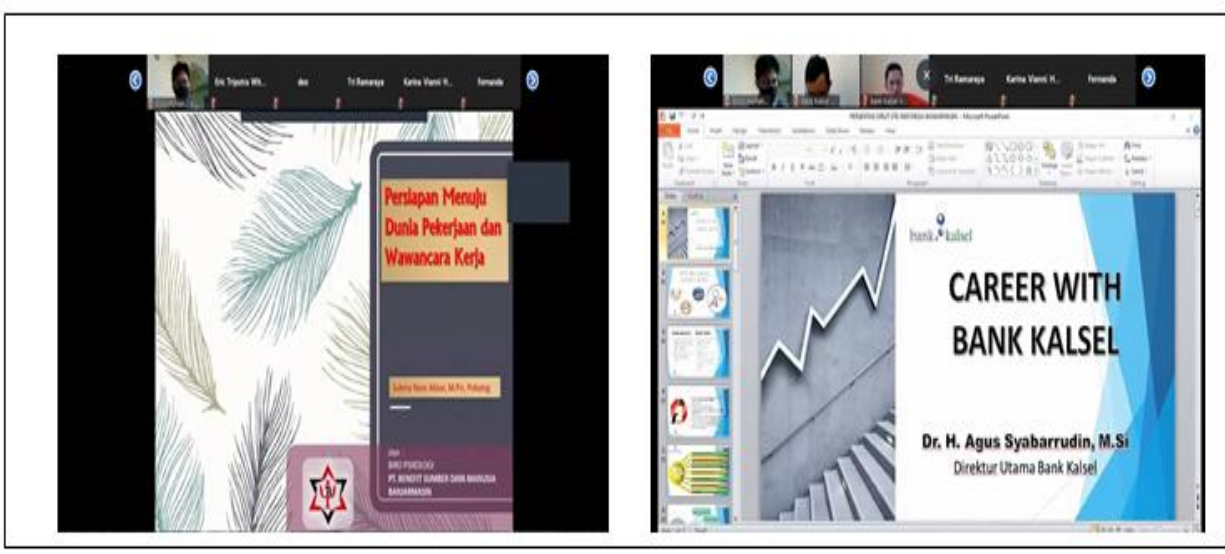

Gambar 2. Pelaksanaan Kegiatan Secara Daring (Webinar) 


\section{SIMPULAN}

Dari kegiatan Pengabdian pada Masyarakat ini dapat disimpulkan hal-hal sebagai berikut :

1. Peserta mengharapkan kegiatan dapat berlangsung lebih baik lagi, terutama pemberian materi yang dapat membantu mereka saat memasuki dunia kerja.

2. Peserta menharapkan pelatihan berupa stimulasi agar mereka dapat lebih efektif dan efesien dalam menghadapi tes masuk kerja, baik berupa tes tertulis maupun tes wawancara.

3. Pelaksanaan kegiatan ini telah berlangsung dengan baik dan efektif, berdasarkan hasil evaluasi diperoleh nilai 3,2 dari 4

Selain itu, berdasarkan kritik dan saran yang diberikan oleh peserta dapat disimpulkan bahwa peserta mengharapkan kegiatan dapat berlangsung lebih baik lagi, terutama pemberian materi yang dapat membantu mereka saat memasuki dunia kerja. Selain itu, peserta juga mengharapkan pelatihan berupa simulasi agar mereka dapat lebih efektif dan efisien dalam mempersiapkan diri mereka untuk menghadapi tes masuk kerja, baik berupa tes tertulis maupun tes wawancara.

\section{UCAPAN TERIMAKASIH}

Teriring ucapan terima kasih kepada STIE Indonesia Banjarmasin yang telah memfasilitasi kegiatan ini. Ucapan terima kasih juga dihaturkan kepada narasumber Dr. Agus Syabarrudin, M.Si,, Direktur Utama Bank Kalsel dan Sukma Noor Akbar, M.Psi.

\section{DAFTAR PUSTAKA}

Aisyah, F. 2019. 7 Persiapan yang Harus Dilakukan Sebelum Wawancara. (https://rencanamu.id/post/dunia-kerja/persiapan-kerja/7-persiapan-yang-harus-dilakukansebelum-wawancara-kerja)

Krishnan, I. A., Ramalingam, S. J., Ching, H. S., dan Maruthai, E. 2017. The Selection Practices and Recruitments of Fresh Graduates in Local Organisation's Job Interview, Journal of Language and Communication, 4(2).

Nghi, N. Q., dan Hien, L. T. D. 2020. Factors Affecting Job Searching Ability of Fresh University Graduates in the Mekong Delta, Vietnam, International Journal of Research and Review Vol.7; Issue: 4.

Nurjanah, A. S. 2018. Kecemasan Mahasiswa Fresh Graduate Dalam Melamar Pekerjaan, Al-Ittizaan: Jurnal Bimbingan Konseling Islam, Vol. 1, No. 2.

Nurullaili, S. 2019. Fenomena Pengangguran Terdidik di Tengah Persaingan Dunia Kerja (Studi Kasus di Desa Pringgadani Kecamatan Sidoarjo Kabupaten Sidoarjo). Skripsi. Program Studi Sosiologi Fakultas Ilmu Sosial dan Ilmu Politik Universitas Islam Negeri Sunan Ampel Surabaya 